\title{
Los derroteros político-electorales del intelectual costarricense Rogelio Fernández Güell (1883-1918)
}

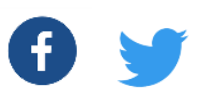

Tomás Federico Arias Castro*

DOI 10.35242/RDE_2019_27_13

Nota del Consejo Editorial

Recepción: 11 de octubre de 2018.

Revisión, corrección y aprobación: 13 de diciembre de 2018.

Resumen: El presente artículo de investigación histórica expone un pormenorizado recuento de los episodios, particularidades, periplos y vicisitudes de naturaleza político-electoral que acontecieron durante la vida del intelectual costarricense Rogelio Fernández Güell (1883-1918), quien se distinguió desde temprana edad y a lo largo de toda su existencia, por una multifacética serie de accionares en diversos aspectos del quehacer cultural y académico de países como Costa Rica (su patria), España, México, EE.UU. y Argentina. Así, se presentan sus primeras incursiones políticas, a inicios del siglo XX, las cuales conjugó con un pionero ejercicio del periodismo y la literatura, a lo que se une el relato de sus derroteros en suelo español y mexicano, en este último país viviría como protagonista directo las incidencias de la afamada Revolución Mexicana, lo que le significaría una profunda y valiosa amistad con el presidente mexicano Francisco I. Madero. Por último, se explican los motivos de su regreso a Costa Rica, el papel que jugó en las elecciones de 1913-1914, sus desempeños funcionales, literarios y académicos en dicha coyuntura, su participación en la rebelión organizada contra el presidente Federico Tinoco Granados y las trágicas incidencias que propiciaron su ignominioso asesinato en marzo de 1918.

Palabras clave: Historia política / Historia electoral / Participación política / Dictadura / Rebelión / Biografía / Fernández Güell, Rogelio.

Abstract: This historical research article presents a detailed account of the episodes, particularities, journeys and vicissitudes of political-electoral nature that took place during the life of the Costa Rican intellectual Rogelio Fernández Güell (1883-1918), who distinguished himself from an early age and throughout his life, by a multifaceted series of actuators in various aspects of cultural and academic work in countries such as Costa Rica (his homeland), Spain, Mexico, USA. and Argentina. His first political incursions were at the beginning of the 20th century which he combined with a pioneering exercise in journalism and literature. In addition, there is the story of his paths on Spanish and Mexican soil, this being the last country where he would live as a direct protagonist of the incidences of the famous Mexican Revolution, which would mean a deep and valuable friendship with the Mexican President Francisco I. Madero. Finally, he explains the reasons for his return to Costa Rica, the role he played in the elections of 1913-1914, his functional, literary and academic performances at that juncture, his participation in the organized rebellion against President Federico Tinoco Granados and the tragic incidents that led to his ignominious murder in March 1918.

Key Words: Political history / Electoral history / Political participation / Dictatorship / Rebellion / Biography / Fernández Güell, Rogelio.

\footnotetext{
* Costarricense, abogado y politólogo, toarca@costarricense.cr. Coordinador y docente de la Cátedra de Historia del Derecho de la Facultad de Derecho de la Universidad de Costa Rica, docente de Historia de la Masonería y de Historia bilateral entre las Repúblicas de Costa Rica y México en el programa de extensión docente de la Escuela de Estudios Generales de la Universidad de Costa Rica y docente de Historia del Derecho Costarricense en la Universidad Escuela Libre de Derecho. Presidente de la Academia Costarricense de Ciencias Genealógicas. Vicepresidente del Consejo Directivo de la Editorial Costa Rica en representación de la Universidad de Costa Rica. Académico Correspondiente de la Academia Morista Costarricense. Integrante de la Sociedad de Amigos de la Academia Mexicana de la Historia.
} 


\section{DERECHO ELECTORAL}

\section{INTROITO}

Desde sus más remotos antecedentes independentistas, la historia de Costa Rica ha presentado la singularidad de contar con una serie de personajes que se han destacado en las más diversas facetas del fenómeno político, ya sea como ilustres oradores, brillantes escritores, pioneros fundadores, aguerridos dirigentes o carismáticos líderes. Esa situación explica y sustenta gran parte del andamiaje democrático que tradicionalmente ha distinguido a nuestra nación en sus ya casi doscientos años de existencia autónoma.

Empero, lo que no ha sucedido con reiteración es la existencia frecuente de individuos que hubiesen logrado reunir -en su sola persona- todas las cualidades antes mencionadas. Precisamente, resulta lógico inferir que una concatenación de esa índole es, siempre, una excepcionalidad que acontece en muy especificas, señaladas y determinantes coyunturas.

Así, en el período comprendido entre las dos últimas décadas de la centuria decimonónica y los casi dos primeros decenios del siglo XX, la historia costarricense atestiguó la vida, pensamiento, obra y derroteros del intelectual Rogelio Fernández Güell, quien no solo se erigió en uno de los compatriotas de más alto fuste intelectivo-cultural de nuestro medio, sino que se destacó en una pléyade de improntas de la más variada naturaleza, entre las que cabe destacar sus acciones como diplomático, masón, espiritista, poeta, académico, funcionario gubernamental, periodista, literato, diputado constituyente, filósofo, polemista, orador y líder revolucionario.

El artículo pretende exponer una de las vertientes a las que Fernández Güell se dedicó con más ahínco y pasión: la rama político-electoral. La cual, dicho sea de paso, fue la que también provocó su oprobiosa y repentina muerte apenas a los 34 años de edad.

\section{LOS PRIMEROS ACCIONARES ELECTORALES}

Rogelio Fernández Güell nació el 4 de mayo de 1883 (Zeledón, 2013, p. 421) en una de las familias de más reconocido abolengo genealógico de nuestro país, cuyos integrantes se venían destacando, desde la otrora época colonial, en diversos cargos y desempeños asociados a la política.

Cabe señalar a su bisabuelo Félix Fernández Tenorio a quien le correspondió el honor histórico de haber sido designado, en 1821, como último 


\section{DERECHO ELECTORAL}

gobernador del entonces territorio español de Costa Rica (Obregón, 1979, p. 147); sin embargo, no ejerció dicho puesto debido a la emancipación de nuestro territorio en aquella ocasión histórica. Asimismo, fue nieto de Manuel Fernández Chacón quien, junto a una gran cantidad de labores públicas y privadas, fungió también como jefe de Estado interino de Costa Rica entre los meses de marzo y mayo de 1835 (Vinatea y Fernández, 2011, p. 69).

Fue hijo del general. Federico Fernández Oreamuno, quien fuese un destacado militar en la Campaña Nacional 1856-1857, fundador y primer gobernador de la actual ciudad de Limón y gobernador de la ciudad de San José (Monge, 1959, pp. 2-3). También fue sobrino del general Próspero Fernández Oreamuno, quien ejerció la presidencia de Costa Rica entre 1882 y 1885 (Obregón, 1991, p. 94), así como también sobrino de la señora Pacífica Fernández Oreamuno, primera dama del país en los bienios 18471849 y 1866-1868 (Fernández, Sáenz y Muñoz, 2001, p. 107), al ser la esposa del gobernante Dr. José María Castro Madriz.

Por lo que, como queda claramente establecido, la práctica política no solo venía siendo una constante en su círculo familiar, sino que, desde la más remota infancia, Fernández Güell tuvo la valiosa ocasión de convivir en un medio idóneo para comenzar a desarrollar las aptitudes que lo distinguirían en años posteriores.

Ahora bien, tras cursar la educación escolar y secundaria en el Liceo de Costa Rica (esta última no finalizó), el joven Fernández, ya con 18 años, incursionó -por primera vez- en tres actividades que conjugó bajo un mismo fin: la política, el periodismo y la escritura.

Lo anterior por cuanto fue en 1901 y bajo el pseudónimo de Bachiller Sansón Carrasco (Celis de la Cruz, 2013, p. 167), cuando rubricó, en periódicos como El Tiempo, El Día y Don Quijote, una serie de artículos de crítica contra el entonces presidente de la República, Rafael Iglesias C., quien pretendía designar al Lic. Ascensión Esquivel I. como su futuro sucesor por medio de una matráfula electoral denominada como La Transacción (Molina, 1999, p. 10). Pues, en efecto, Iglesias había negociado con los principales partidos políticos de ese momento para que Esquivel asumiese la dirección del Poder Ejecutivo en 1902. Tal denuncia le valió a Fernández una fuerte persecución gobiernista y la aplicación de una ilegítima sanción punitiva de 20 días de prisión (Gutiérrez, 2017, p. 78). 


\section{DERECHO ELECTORAL}

Tras cumplir la sentencia, Fernández retomó con más ahínco sus cuestionamientos contra el binomio Iglesias-Esquivel, para lo cual incluso fundó, en septiembre de 1901, su primer periódico con el nombre El Derecho (Morales, 1995, p. 119). A ello se agregó otro de igual importancia, pues dicho órgano periodístico aglutinó a múltiples ciudadanos que, tras no apoyar La Transacción y habiendo formado parte del entonces recién creado Partido Republicano (1897), respaldaron la candidatura del jurista Máximo Fernández A. para los próximos comicios (Salazar, 1975, pp. 327-332). Propuesta que, sin embargo, no logró su objetivo, pues, tras varias arbitrariedades electorales, Esquivel se convirtió en el nuevo mandatario de Costa Rica (Arias, 2013, p. 98).

De seguido, este resultado político le significó a Rogelio Fernández un virulento panorama, pues, poco después y debido a su verbo locuaz y fama creciente, sufrió un artero ataque físico por parte de varios militares en la ciudad de San José, lo que le ocasionó una lesión perenne en su mano derecha (Oconitrillo, 1981, p. 40); también, fueron perseguidos su familia y sus compañeros de labor periodística. Todo lo cual hizo que renunciase a El Derecho y se trasladase a vivir al cantón de Atenas. Mas lo cierto es que las vejaciones no cesaron, por tanto, comprendiendo que su vida estaba en peligro, optó por abandonar nuestro país en búsqueda de nuevos horizontes intelectuales.

\section{LA AVENTURA ESPAÑOLA Y MEXICANA}

Fue en febrero de 1904 cuando Rogelio Fernández arribó a la nación que había escogido como nuevo destino de su vida: España (Segura, 1963, p. 66); decisión fundamentada no solo en su interés en cursar estudios universitarios y desarrollar su talento literario, sino por la gran cantidad de familiares maternos suyos que vivían en dicho país europeo.

Sin embargo, dado que la temática de este estudio trata sobre los aspectos político-electorales de tal personaje (en los cuales no incursionó en suelo ibérico), basta con señalar que fue en ese territorio en donde ingresó como pasante a la Universidad de Madrid, laboró como articulista y poeta en varias revistas literarias y esotéricas, se inició en la doctrina filosóficareligiosa del Espiritismo (Abbagnano, 1963, p. 442) y contrajo matrimonio, en 1906, con la señorita catalana Rosa Serratacó (Quesada, 1921, p. 95). Esas nupcias, al no contar con el aval familiar de la contrayente, llevaron a 


\section{DERECHO ELECTORAL}

la joven pareja a salir de España, esto para Fernández significó el segundo de sus autoexilios.

En ese sentido y con el fin de continuar con sus intereses literarios, espiritistas y académicos, Rogelio Fernández y su esposa se enrumbaron a una de las principales metrópolis intelectivas de Latinoamérica: Ciudad de México. Este hecho repercutiría ostensiblemente en sus vidas.

Una vez en tierras mexicanas (1907) y debido a las conexiones que había alcanzado por su afiliación al espiritismo, Fernández trabajó como funcionario del Observatorio Astronómico Nacional (Fernández, 1918, p. 12), misma época en la que retomó su labor de escritor con varios folletos y artículos de temática espiritista. Unos meses más tarde y otra vez por su ligamen al espiritismo, laboró como bibliotecario de la Secretaría de Relaciones Exteriores de México. A finales de 1907, su amigo y colega espiritista Ignacio Mariscal, entonces canciller de México (Quijano, 2012, pp. 255), lo designó como Cónsul de ese país en la ciudad estadounidense de Baltimore (González, 2009, p. 44), por lo que, ya para inicios de 1908, se encontraba en la nación anglosajona, donde viviría por los próximos tres años.

No obstante, la estadía de Fernández Güell en EE.UU. feneció por dos aspectos de importancia para su persona. Así, por una parte, fue en 1910 cuando las autoridades diplomáticas mexicanas establecieron como requisito para laborar en la Cancillería el que se ostentase la nacionalidad de ese país o que se obtuviese esta por naturalización, a lo que Fernández argumentó:

Con gusto aceptaría la nacionalidad mexicana, porque pienso que un latinoamericano está en su propio país en cualquiera de las Repúblicas del mundo de Colón y porque México es para mí tan querida como aquella (tierra) en que vi la luz; pero no me avengo a renunciar a mi nacionalidad por conservar una posición. Si esa renuncia me fuera pedida porque así lo requiere la salud, el bienestar o la prosperidad de México, en el acto me hubiera sentido mexicano. (Fernández, 1918, p. 12).

A lo anterior y junto a su renuncia al servicio exterior mexicano, se unió la circunstancia histórica de que dicha nación se encontraba, desde mediados de 1910, en los prolegómenos de la afamada Revolución Mexicana (Knight, 2010, p. 251), cuyo principal líder era el acaudalado empresario, dirigente 


\section{DERECHO ELECTORAL}

político y ferviente espiritista, Francisco I. Madero González (Krauze, 1987, p. 11). Así, tanto por los draconianos métodos represivos que el gobierno del entonces presidente Porfirio Díaz Mori (Torres y Villegas, 2010, pp. 225-228) había implementado contra los revolucionarios (los que resultaron intolerables para Fernández) como por su ligamen espiritista con Madero, el intelectual costarricense decidió unirse a la lucha revolucionaria, por lo que viajó, en abril de 1911, al limítrofe estado de Chihuahua, sede del campamento de Madero, para conocerlo, una vez ahí comentó:

Busqué con la mirada al jefe de la Revolución, imaginando encontrar a un hombre alto y membrudo y grande fue mi sorpresa cuando vi que todos se dirigían a un individuo vestido de kaki, moreno, de barba y bigotes negros, de pobladas cejas, enjuto de carnes, nervioso y de voz un poco recia [...] Madero me dirigió una mirada como preguntándome quién era. Su padre me nombró y Madero, entonces, alargóme la mano, una mano vellosa y fuerte que estreché con la misma franqueza con que se me tendía y le expuse el motivo de mi viaje [...] Madero me invitó a dar una vuelta por el campo, ascendimos a una colina cercana y desde allí me mostró la posición de las fuerzas revolucionarias. Con increíble agilidad subía por los lugares más escarpados, en tanto que yo buscaba las pendientes suaves. [...] En mi conversación con el señor Madero, nuevamente se reveló el hombre altruista, el filósofo de miras amplias y de sentimientos elevados de quien yo tenía noticia. (Fernández, 1915, pp. 67-68).

En consecuencia, Madero y Fernández iniciaron una profunda relación de amistad y respeto intelectual mutuo, la cual se consolidó con la participación activa que el segundo asumió a partir de ese momento en el proceso revolucionario. De seguido, fue en mayo de 1910, cuando Fernández regresó a Ciudad de México, y a finales de ese mismo mes el presidente Díaz presentó su renuncia (Villalpando y Rosas, 2009, pp. 173-175), lo que propició el triunfo total de la lucha revolucionaria de Madero.

\section{LA IMPRONTA ELECTORAL EN MÉXICO}

Con el fin de legitimar su liderazgo ante la ciudadanía mexicana, fue a mediados de 1911 cuando el triunfante líder Francisco Madero presentó su candidatura a la presidencia de ese país. Casi de inmediato y para contar con un ente periodístico que asumiese la labor propagandística de su 


\section{DERECHO ELECTORAL}

candidatura, Madero le solicitó dicha acción a su ahora amigo Rogelio Fernández, quien fundó entonces, en julio de 1911, el periódico El Amigo del Pueblo: órgano oficial del club "Libertador Francisco I. Madero" (Arias, 2015 , p. 54) asumiendo, asimismo, su dirección general, lo cual sumó a la función que ya ejercía como secretario del citado club partidista.

Empero, la actividad proselitista de más importancia que Fernández Güell ejerció a favor de Madero fue la redacción del opúsculo biográfico El moderno Juárez: estudio sobre la personalidad de don Francisco I. Madero (Barrón, 2010, p. 191). Ahí el costarricense expuso la vida y obra del mexicano para contrarrestar varias difamaciones electoreras que se habían vertido en su contra; en ese texto señaló:

No es posible que una personalidad, por brillante que sea, carezca de detractores, los que forman, por decirlo así, el fondo oscuro que hace resaltar sus virtudes. En el momento del triunfo, las envidias, los despechos y los rencores callaron ahogados por el aplauso ensordecedor con que las multitudes saludaron el resurgimiento esplendoroso de las libertades patrias. Hablar contra Madero, zaherirlo en cualquier sentido hubiera sido impolítico. Así, aquellos sentimientos perversos enmudecieron y la envidia y el rencor guardaron sus puñales. Más pasado ese momento psicológico en el alma de las multitudes, extinguido en el espacio el eco de las aclamaciones con que saludaron al líder, atenuado en algún tanto el recuerdo de su entrada triunfal, los enemigos han vuelto a aparecer, más rabiosos que nunca, dispuestos a formar por todos los medios, una cruzada contra el Apóstol de la Democracia. (Fernández, 1911, pp. 4-16).

A continuación, las elecciones se efectuaron en octubre, abrumadoramente ganadas por Madero y su candidato vicepresidencial Lic. José M. Pino Suárez (Poblett, 1986, p. 32), por lo que ambos iniciaron su mandato en noviembre de 1911.

Ahora bien, vuelva a reiterarse, aún cuando el objeto de este artículo está referido a los accionares político-electorales de Fernández (los cuales cesaron en México tras el triunfo de Madero), cabe indicar que, entre los citados años de 1911 y 1913, se desempeñó como jefe del Departamento de Publicaciones del Museo Nacional de Arqueología, Historia y Etnología, fue director del periódico La Época, redactor del periódico Nueva Era, director de la revista espiritista Helios e integrante de la Masonería de ese 


\section{DERECHO ELECTORAL}

país y presidente de la Gran Liga Mexicana de Librepensadores (Gutiérrez, 2017, p. 95).

Sin embargo, la faceta más honrosa que Rogelio Fernández protagonizó en suelo mexicano fue la que le asignó el presidente Madero en octubre de 1912 (Zeledón, 2013, p. 421), pues lo nombró como quinto director de la afamada Biblioteca Nacional de México (Carrasco, 1947, p. 11), siendo hasta el presente el único extranjero en haber tenido la valiosa oportunidad de ejercer dicho puesto público. Por lo que:

Ninguno de los cargos que hasta ahora ha ocupado lo llena tanto de orgullo como éste. Está en su elemento: los libros. Todas las mañanas al pasar a su despacho tiene que caminar entre dos hileras de mármoles de tamaño natural, que en aquel ambiente conventual parecen santos; pero son estatuas de Herodoto, Dante, Petrarca, Shakespeare, Goethe, Hugo y otros genios de la literatura universal que custodian el claustro. (Oconitrillo, 1981, p. 65).

De modo lamentable, la estadía de Fernández Güell en México feneció por el siniestro episodio conocido como la Decena Trágica (Villalpando, 2009, p. 11) cuando en diez aciagos días, acaecidos entre el 9 y el 19 de febrero de 1913 (Martín, 2009, pp. 97-108), se defenestró al presidente Francisco Madero tras un planificado golpe de Estado que colocó como nuevo e ilegítimo gobernante al pérfido gral. Victoriano Huerta Márquez (Molina, 2008, pp. 254-257). Esto sucedido, en la noche del viernes 22 de febrero siguiente del asesinato ignominioso de Madero y el vicepresidente Pino (Sotomayor, 2016, pp. 17-21), tras ser acribillados, por orden de Huerta, en la muralla trasera de la penitenciaría federal de Lecumberri (Gómez, 2008, pp. 39-45), la cual se erigía como la principal cárcel de la Ciudad de México.

Así las cosas y ante la aprehensión que Huerta había dictado en su contra por su reconocida amistad con Madero; Fernández y su familia huyeron de la capital mexicana (Tortolero, 2004, p. 221), pudiendo únicamente llevar algunos enceres personales, pues todas sus pertenencias les fueron incautadas.

Fue entonces cuando el intelectual costarricense, tras nueve largos años de ausencia, tomó la determinación de volver a Costa Rica, para lo cual se embarcó. 


\section{DERECHO ELECTORAL}

\section{NueVAS COYUntURAS ELECTORALES}

Rogelio Fernández regresó a suelo costarricense en marzo de 1913, encontrándose con dos agradables noticias políticas. Por una parte, el Partido Republicano por el que tanto había luchado en 1902, ahora se encontraba ejerciendo por vez primera el Poder Ejecutivo en la figura del Lic. Ricardo Jiménez Oreamuno (Vargas, 1986, p. 264); mientras que el proceso electoral para el cuatrienio 1914-1918 presentaba como uno de los candidatos a su entrañable amigo, el ya antes citado Lic. Máximo Fernández A., quien se enfrentaba a los expresidentes Rafael Iglesias y Carlos Duran Cartín (Salazar, 2002, pp. 231-240).

Fue entonces cuando Fernández se involucró en la contienda de cita, asumiendo el destacado papel de articulista político en el periódico partidista El Republicano, respecto del cual, además, asumió luego su dirección a las pocas semanas.

Asimismo, Fernández redactó un folleto proselitista bajo el título de Máximo Fernández ante la historia y ante sus contemporáneos: ensayo biográfico (Gutiérrez, 2017, pp. 96-97), en cuyas páginas no solo expuso diversos hechos sobre la vida de ese jurista y político, sino que refutó algunos cuestionamientos y diatribas en su contra

Al referirnos a Máximo Fernández [...] ese que veis cruzar bajo arcos de triunfo y lluvias de flores, con el rostro iluminado por una bondadosa sonrisa y la noble frente tostada por los soles del Guanacaste y refrescada por las brisas del Pacífico, no es un guerrero victorioso que con la espada en la mano deslumbra y ahuyenta al enemigo, ni un soberbio Jefe de Estado que pasa con el boato de su alta jerarquía, sino un modesto ciudadano que, desde su juventud, ha luchado por los derechos del pueblo y que con paso firme se dirige a recibir, ante el ara santa de la Patria, de manos del actual mandatario, la corona de laureles que la República reserva a sus hijos predilectos [...] Nadie como él ha sido más aclamado y más combatido; nadie como él ha resistido el oleaje de las pasiones enemigas con la inquebrantable firmeza de una roca; nadie, en suma, ha sido más analizado, discutido, vituperado y aplaudido. Con sus hechos, llena veinte años de nuestra vida nacional y su vida está para siempre vinculada a nuestra historia. (Fernández, 1913, pp. 5-14). 


\section{DERECHO ELECTORAL}

Empero, tras las elecciones (diciembre, 1913), ninguno de los tres contendientes alcanzó la entonces mayoría del 50\% para acceder al solio presidencial, por lo que, tras meses de intrigas y artilugios, las fuerzas políticas partidistas convinieron en que el diputado republicano Alfredo González Flores se convirtiese en el nuevo mandatario en ejercicio desde mayo de 1914 (Rodríguez, 1978, pp. 84-85).

Lo anterior hizo que Fernández Güell volviese a sus menesteres personales y funcionales, destacando su incorporación al órgano cultural El Ateneo de Costa Rica, así como sus facetas de subsecretario de Gobernación y Policía, subsecretario de Fomento y director general de Correos (Oconitrillo, 1981, p. 81). Aunado a ello, retomó su labor literaria, resaltando por su importancia la obra de 1915: Episodios de la Revolución Mexicana (Arias, 2015, pp. 180-208), en la que, haciendo un uso magistral de la filología y exponiendo una gran sapiencia en temas de cultura universal, narró los históricos acontecimientos que había atestiguado durante su estadía en México, haciendo énfasis en la oprobiosa ejecución del presidente Madero, respecto de la cual expuso:

El paso de los grandes espíritus por la tierra se señala siempre con cataclismos y conflagraciones. Los baluartes del error y de la mentira se derrumban, las sociedades se conmueven en sus cimientos y el océano popular se encrespa y ruge, en tanto que el Sinaí y el Gólgota se coronan de relámpagos y rayos. Madero, predestinado para reformar una sociedad, donde el despotismo y la injusticia habían echado hondas raíces, pasó por el cielo de México con la brillante claridad de un meteoro, y su noble espíritu, incapaz de contenerse en la arcilla humana, desapareció como el de Numa, envuelto en la tempestad que había suscitado. (Fernández, 1915, pp. 244-245).

A continuación, Fernández fundó y asumió la dirección general de un nuevo periódico (septiembre, 1915), al que denominó El Imparcial (Rodríguez, 1976, p. 77), este rápidamente se posicionó como uno de los más leídos de su época. Luego de ello y por designio del presidente González, volvió a la administración pública en marzo de 1916, al nombrársele enviado diplomático de Costa Rica ante los gobiernos de Argentina, Brasil y Chile (Arias, 2016, pp. 95-98), hasta que regresó a Costa Rica en julio de ese mismo año. 


\section{DERECHO ELECTORAL}

Sin embargo, su estadía en nuestra nación fue corta, pues un mes más tarde viajó a España junto a su familia, periplo realizado con motivo de varios afanes literarios que Fernández materializó en dicho país (Gutiérrez, 2017, p. 98) donde se mantuvo hasta fines de ese año.

\section{EL COMIENZO DEL FIN}

Fue en marzo de 1917 cuando Rogelio Fernández regresó a Costa Rica, donde se encontró con la noticia de que el mandatario González había sido defenestrado por el gral. Federico Tinoco Granados (Murillo, 1981, pp. 17-31), quien ejercía ahora el mando interino de nuestro territorio.

En ese sentido, lo anterior representó para Fernández una singularidad, pues habiendo conocido a Tinoco desde su juventud, poseía con este una sólida amistad y homogeneidad política, ambos eran integrantes del Partido Republicano. A esto se unió el vínculo genealógico-familiar que poseía con la señora María Fernández Le Cappellain (Fernández, Sáenz y Muñoz, 2001, pp. 493-501), quien no solo era su prima, sino también la esposa de Tinoco Granados.

De seguido, Fernández Güell reasumió la dirección de su periódico El Imparcial, pero, debido a su prestigio, resultó electo, en abril de 1917 (Zeledón, 2013, p. 422), como diputado constituyente por la provincia de San José, en virtud de la convocatoria que el gral. Tinoco había realizado para dotar a Costa Rica de una nueva Constitución Política.

Así las cosas, Rogelio Fernández se destacó por su oratoria y sapiencia, pero, sobre todo, por su férrea oposición a varios proyectos que el Poder Ejecutivo presentó ante el órgano constituyente. Sobre todo en lo referente a la reinstalación de la pena de muerte, derogada en 1882 (Guier, 1968, p. 1182), y a la restauración del voto indirecto para la elección presidencial, eliminado en 1913 (Obregón, 2000, p. 243). Todo lo cual hizo que la otrora cordialidad que mantenía con Tinoco empezase a resquebrajarse, pues no estaba dispuesto a claudicar en ninguno de sus ideales y principios.

Fue entonces cuando la idea de implementar las ejecuciones penales fue rechazada (Gómez, 1985, p. 133), lo cual le valió un gran respaldo de la ciudadanía. No obstante, el proyecto de voto indirecto sí fue aprobado, por lo que Fernández renunció entonces al Congreso Constituyente en mayo (Fernández, 2010, p. 153), pues calificó ese episodio como una imposición 


\section{DERECHO ELECTORAL}

del Poder Ejecutivo, lo que, unido a sus críticos artículos en El Imparcial, aumentó todavía más el diferendo con Tinoco.

Por fin, fue en junio cuando se emitió la llamada Constitución Política de 1917 (Zeledón, 1946, p. 261). En ese mes Fernández volvió al plenario cuando se instaló el Congreso ordinario (Obregón, 1995, p. 427), pues dicha norma fundamental había dispuesto que los antiguos constituyentes asumiesen como nuevos diputados, oportunidad que Fernández atisbó como idónea, dada la inmunidad de que gozaba, para arremeter contra Tinoco y su Gabinete. Como en efecto lo hizo.

Empero, el punto de inflexión entre ambos acaeció un mes más tarde, cuando Tinoco ordenó el allanamiento y clausura de El Imparcial (Quesada, 1921, pp. 9-11). Desde ese momento se convirtieron en furibundos enemigos.

Con el pasar de los meses, tanto los cuestionamientos de Fernández contra Tinoco, como las imprecaciones de este contra el primero, recrudecieron ostensiblemente, hasta que, en noviembre de 1917 (Chacón, 1920, p. 144), el Gobierno ordenó la captura de dicho intelectual tras acusársele de estar involucrado en una inminente rebelión. Sin embargo, Fernández continuó asistiendo al plenario en virtud de la inmunidad que lo amparaba hasta mediados de diciembre cuando no se apersonó más en resguardo de su vida (Junoy, 2014, pp. 68-69), por lo que, por el resto de 1917, se ocultó en las casas de varios conocidos, pues la suya fue perennemente vigilada.

\section{LOS ÚLTIMOS AVATARES}

Iniciado el año 1918, Rogelio Fernández se dedicó -durante enero- a preparar la logística de la lucha revolucionaria que venía proyectando desde 1917. Finiquitados todos los detalles, dicho episodio bélico inició el 22 de febrero de 1918 (Fernández, 2010, p. 206); fecha escogida por conmemorarse ese día el quinto aniversario fúnebre del asesinado presidente Madero.

De modo lamentable, la llamada Rebelión de río Grande (Fernández, 1984, p. 141), pues su primer acto se verificó en dicha vía fluvial por el cantón de Atenas, fue rápidamente vencida por el Gobierno, dado que, junto a la carestía de armas, pertrechos y municiones, aconteció también el nimio 


\section{DERECHO ELECTORAL}

apoyo de la población, así como una desafortunada serie de erróneas decisiones tácticas (Fischel, 1992, p. 142).

Fue así que a los pocos días, Fernández Güell optó por dirigirse a la República de Panamá para continuar su lucha, puesto que en dicho país había un grupo de costarricenses preparando otra rebelión (Volio, 1973, p. 55). Esa decisión tuvo tintes de odisea, pues recorrió nuestro territorio a pie desde la ciudad de Orotina hasta la frontera sur, voluntariamente acompañado por cuatro correligionarios.

Después de una serie de vicisitudes, en donde incluso fueron guiados por un habitante indígena (Oconitrillo, 1981, p. 114), el pequeño grupo revolucionario arribó al pueblo de General Viejo en el actual cantón de Pérez Zeledón (marzo, 1918), momento en que, tras la unión de otro adepto, se enteraron de la existencia de un batallón policial que se dirigía para aprehenderlos, cuya autoridad era ejercida por el teniente coronel. Patrocinio Araya (Sancho, 2010, p. 15). Por esa razón, se enrumbaron entonces al cercano poblado de Buenos Aires (Aguilar, 2008, p. 167), para así evitar a sus perseguidores.

No obstante, el destino de Fernández y sus acólitos fue otro, pues el viernes 15 de marzo de 1918 (Arias, 2015, p. 55) y tras la delación de un habitante local que los avistó, fueron atacados de modo alevoso por las tropas de Araya en las cercanías del río Ceibo (Revollo, 2012, p. 25). Así, en lo concerniente a Fernández Güell, quien se rindió y desarmó, fue el propio Araya quien le disparó en la cabeza, el cuello, el pecho y las piernas (López, 1919 , p. 41). Luego de lo cual, el batallón procedió a robarles las pertenencias a todas las víctimas.

Con posterioridad, los cinco cadáveres, pues solo un revolucionario y el guía indígena sobrevivieron, fueron enterrados en el cementerio de Buenos Aires (Chacón, 1986, p. 88), gracias a los menesteres del maestro salvadoreño Marcelino García Flamenco (Picardo, 2004, p. 192), docente de dicha localidad y testigo directo de los homicidios, quién se traslada a Panamá y denuncia los asesinatos en el periódico Star and Herald (Dobles, 1934, pp. 395-396), lo que posibilitó que los costarricenses conociesen los detalles turbios en que se habían perpetrado.

Para 1920 el Congreso dispuso que los restos de Fernández y sus compañeros fuesen exhumados y trasladados al Cementerio General de San José, lo cual se ejecutó hasta 1923 (Oconitrillo, 1981, p. 123), cuando se 


\section{DERECHO EIECTORAL}

les depositó en un mausoleo de la Masonería costarricense (Arias, 2016, p. 98), en donde se encuentran hasta la actualidad.

Así, a partir de ese momento, la figura de Rogelio Fernández Güell entró a formar parte imperecedera del acervo cívico de nuestra Patria con todo merecimiento y valía, cumpliéndose en 2018 el centenario histórico de su muerte.

\section{REFERENCIAS BIBLIOGRÁFICAS}

Abbagnano, N. (1963). Diccionario de Filosofía. México D.F.: FCE.

Aguilar, O. (2008). Federico Tinoco Granados...ante la historia. San José: Progreso Editorial.

Arias, T. (2014). El Canciller Esquivel Ibarra (biografía e impronta del Lic. Ascensión Esquivel Ibarra). San José: Ministerio de Relaciones Exteriores y Culto e Instituto del Servicio Exterior.

Arias, T. (2015). Las Repúblicas de México y Costa Rica durante la Revolución Mexicana (1910-1920). Revista Estudios, (29), 51-65.

Arias, T. (2015). Centenario de la primera obra literaria costarricense sobre la historia de la Revolución Mexicana (1915-2015). Revista Estudios, (31), 180-208.

Arias, T. (2016). México (1907) y Argentina (1916): los derroteros diplomáticos del literato, filosofo, político y masón Rogelio Fernández Güell. Revista Decisiones: la huella en la política, (2), 95-98.

Barrón, L. (2010). Historias de la Revolución Mexicana. México D.F.: FCE.

Carrasco, R. (1947). Historia de la Biblioteca Nacional de México. México: UNAM.

Celis de la Cruz, C. (2013). Rogelio Juan Fernández Güell en México (1883-1918). En: XII Jornadas Académicas 2010 (compendio). México: UNAM.

Chacón, T. (1920). Proceso histórico (tomos I y II). San José: Imprenta Falcó y Borrase.

Chacón, L. (1986). Buenos Aires: cantón de Puntarenas (apuntes para su historia). Revista del Archivo Nacional, (1-12), 5-166. 


\section{DERECHO EIECTORAL}

Dobles, L. (1934). Índice bibliográfico de Costa Rica, San José: Imprenta Lehmann.

Fernández, J., Sáenz, J., y Muñoz, M. (2001). Las Primeras Damas de Costa Rica. San José: ICE.

Fernández, R. (1984). Cartilla histórica de Costa Rica. San José: Imprenta Lehmann.

Fernández, R. (1911). El moderno Juárez (estudio sobre la personalidad de don Francisco I. Madero). Ciudad de México: Tipografía Artística.

Fernández, R. (1913). Máximo Fernández ante la historia y ante sus contemporáneos (ensayo biográfico). San José: Imprenta Alsina.

Fernández, R. (1915). Episodios de la Revolución Mexicana. San José: Imprenta Trejos Hnos.

Fernández, R. (1918). Poesías. San José.

Fernández, J. (2010). Las Presidencias del Castillo Azul. San José.

Gómez, C. (1985). La pena de muerte en Costa Rica durante el siglo XIX. San José: ECR.

Gómez, M. (2008). Asesinatos políticos en México (1901-1994). México D.F.: Editorial Planeta Mexicana.

González, P. (2009). Un costarricense en la Revolución Mexicana. La Nación (sección Áncora), 44.

Gutiérrez, B. (2017). Un cercano amigo de Francisco I. Madero. Temas de nuestra América (UNA y EUNA), (número extraordinario), 77-104.

Junoy, R. (2014). Satrapía. En: Sánchez Solano, E. El año funesto (Jorge Volio)/Satrapía (Ramón Junoy). San José: EUNED.

Knight, A. (2010). La Revolución Mexicana (del Porfiriato al nuevo régimen constitucional). México D.F.: FCE.

Krauze, E. (1987). Francisco I. Madero (místico de la libertad). México D.F.: FCE.

López, J. (1919). La caída del Gobierno Constitucional de Costa Rica. New York: De Laisne y Carranza.

Martín, F. (2009). Las grandes traiciones de México. México D.F.: Santillana Ediciones Generales. 


\section{DERECHO EIECTORAL}

Molina, S. (2008). 101 villanos en la historia de México. México D.F.: Editorial Grijalbo.

Monge, D. (1959). Don Próspero Fernández y su Gobierno (Tesis de licenciatura), Universidad de Costa Rica, San José, Costa Rica.

Murillo, H. (1981). Tinoco y los Estados Unidos. San José: EUNED.

Obregón, R. (1979). Los Gobernadores de la Colonia. San José: Universidad de Costa Rica.

Obregón, R. (1991). Costa Rica y la guerra contra los Filibusteros. Alajuela: MHCJS.

Obregón, R. (1995). El Poder Legislativo en Costa Rica. San José: Asamblea Legislativa.

Obregón, C. (2000). El proceso electoral y el Poder Ejecutivo en Costa Rica (18081898). San José: EUCR.

Oconitrillo, E. (1981). Rogelio Fernández Güell: escritor, poeta y caballero andante. San José: ECR.

Poblett, M. (1986). José María Pino Suárez (semblanza). México D.F.: INEHRM.

Picardo, O. (2004). Diccionario Enciclopédico de Ciencias de la Educación. San Salvador: C.I.E.

Quesada, O. (1921). El Imparcial. San José: Imprenta Falcó \& Borrasé.

Quijano, M. (2012). Los Gabinetes de México: 1821-2012 (tomo III). México D.F.: INAP.

Rodríguez, A. (1978). Administración González Flores. San José: EUCR.

Salazar, O. (1975). Máximo Fernández. San José: MCJD.

Salazar, O. (2002). El apogeo de la República liberal en Costa Rica (1870-1914). San José: EUCR.

Segura, M. (1963). La poesía en Costa Rica. San José: ECR.

Sotomayor, J. (2016). Magnicidios y ocasos históricos en México. México D.F.: Editorial Porrúa. 


\section{DERECHO ELECTORAL}

Torres, J. y Villegas, G. (2010). Diccionario de la Revolución Mexicana. México D.F.: UNAM.

Tortolero, Y. (2004). El Espiritismo seduce a Francisco I. Madero. México D.F.: Senado de México.

Villalpando, J. (2009). La Decena Trágica. México D.F.: Editorial Planeta.

Villalpando, J. y Rosas, A. (2008). Muertes históricas, México D. F.: Editorial Planeta.

Vinatea, J. y Fernández, R. (2011). Grandes familias de Costa Rica. San José.

Volio, M. (1973). Jorge Volio y el Partido Reformista. San José: ECR.

Zeledón, E. (2013). Biografías costarricenses. Heredia: EUNA.

Zeledón, M. (1946). Digesto Constitucional de Costa Rica. San José: Colegio de Abogados. 